University of Nebraska - Lincoln

DigitalCommons@University of Nebraska - Lincoln

8-2017

\title{
Geographical Variation in Community Divergence: Insights from Tropical Forest Monodominance by Ectomycorrhizal Trees*
}

\author{
Tadashi Fukami \\ Mifuyu Nakajima \\ Claire Fortunel \\ Paul V. Fine \\ Christopher Baraloto
}

See next page for additional authors

Follow this and additional works at: https://digitalcommons.unl.edu/bioscifacpub

Part of the Biology Commons

This Article is brought to you for free and open access by the Papers in the Biological Sciences at DigitalCommons@University of Nebraska - Lincoln. It has been accepted for inclusion in Faculty Publications in the Biological Sciences by an authorized administrator of DigitalCommons@University of Nebraska - Lincoln. 


\section{Authors}

Tadashi Fukami, Mifuyu Nakajima, Claire Fortunel, Paul V. Fine, Christopher Baraloto, Sabrina E. Russo, and Kabir G. Peay 


\title{
Geographical Variation in Community Divergence: Insights from Tropical Forest Monodominance by Ectomycorrhizal Trees*
}

\author{
Tadashi Fukami, ${ }^{1, \dagger}$ Mifuyu Nakajima, ${ }^{1}$ Claire Fortunel, ${ }^{2}$ Paul V. A. Fine, ${ }^{3}$ \\ Christopher Baraloto, ${ }^{4}$ Sabrina E. Russo, ${ }^{5}$ and Kabir G. Peay ${ }^{1}$
}

1. Department of Biology, Stanford University, Stanford, California 94305; 2. Department of Ecology and Evolutionary Biology, University of California, Los Angeles, California 90095; 3. Department of Integrative Biology and University and Jepson Herbaria, University of California, Berkeley, California 94720; 4. L'Institut National de la Recherche Agronomique, Unité Mixte de Recherche Ecologie des Forêts de Guyane, Kourou, French Guiana; and Department of Biological Sciences and International Center for Tropical Botany, Florida International University, Miami, Florida 33199; 5. School of Biological Sciences, University of Nebraska, Lincoln, Nebraska 68588

Online enhancements: supplementary material. Dryad data: http://dx.doi.org/10.5061/dryad.c0kr7.

Aвstract: Convergence occurs in both species traits and community structure, but how convergence at the two scales influences each other remains unclear. To address this question, we focus on tropical forest monodominance, in which a single, often ectomycorrhizal (EM) tree species occasionally dominates forest stands within a landscape otherwise characterized by diverse communities of arbuscular mycorrhizal (AM) trees. Such monodominance is a striking potential example of community divergence resulting in alternative stable states. However, it is observed only in some tropical regions. A diverse suite of AM and EM trees locally codominate forest stands elsewhere. We develop a hypothesis to explain this geographical difference using a simulation model of plant community assembly. Simulation results suggest that in a region with a few EM species (e.g., South America), EM trees experience strong selection for convergent traits that match the abiotic conditions of the environment. Consequently, EM species successfully compete against other species to form monodominant stands via positive plant-soil feedbacks. By contrast, in a region with many EM species (e.g., Southeast Asia), species maintain divergent traits because of complex plant-soil feedbacks, with no species having traits that enable monodominance. An analysis of plant trait data from Borneo and Peruvian Amazon was inconclusive. Overall, this work highlights the utility of geographical comparison in understanding the relationship between trait convergence and community convergence.

Keywords: community assembly, mycorrhizae, plant-soil feedback, plant traits, priority effects, species pools.

\footnotetext{
* This issue originated as the 2016 Vice Presidential Symposium presented at the annual meetings of the American Society of Naturalists.

${ }^{\dagger}$ Corresponding author; e-mail: fukamit@stanford.edu.

ORCIDs: Fukami, http://orcid.org/0000-0001-5654-4785; Nakajima, http:// orcid.org/0000-0001-7778-2029.

Am. Nat. 2017. Vol. 190, pp. S105-S122. (c) 2017 by The University of Chicago. 0003-0147/2017/190\$1-57233\$15.00. All rights reserved. DOI: $10.1086 / 692439$
}

\section{Introduction}

At the species level, convergence is defined by distantly related species sharing similar traits, but convergence is also possible at the community level, in which distantly located communities develop to have similar species abundance distribution, functional group composition, and other aspects of community structure (Fukami 2009). These forms of convergence are thought to result from the predictable response of independently evolved species (e.g., Reich et al. 1997; Conte et al. 2012) and separately assembled communities (e.g., Samuels and Drake 1997; Li et al. 2016) to similar environmental conditions. Identifying factors that promote or prevent convergence is therefore fundamental to the understanding of predictability at both the species and community levels of biological organization (Stern 2013). Despite this duality of convergence, the link between trait convergence and community convergence remains poorly investigated (Cavender-Bares et al. 2009). It may seem obvious that trait convergence automatically translates into community convergence (Melville et al. 2006). As we argue in this article, however, the link may not be so straightforward, particularly when multiple lineages of species converge in traits among themselves but diverge from members of other lineages, which can promote divergence-rather than convergence- of community structure.

How does community convergence and divergence take place? Insights on this question can be found as early as Clements, who developed the climax concept of plant succession (e.g., Clements 1936). According to this well-known concept, communities converge to a predictable species composition determined by the abiotic environment (but see Gleason 1927). More recently, increasing evidence suggests that community divergence - in the form of alternative sta- 
ble states - may be more common than previously thought (Schröder et al. 2005), but understanding when alternative stable states emerge remains a major challenge for community ecologists (Petraitis 2013). Local communities are considered to be in alternative stable states when they diverge in species composition, even though the communities share the same environmental conditions and the same species pool (Fukami 2015). This divergence is driven by priority effects, in which the order or initial abundance in which species arrive influences the effects that species have on one another in local communities (Palmgren 1926; Sutherland 1974; Drake 1991). As factors determining when alternative stable states occur, more attention has been paid to the abiotic conditions of local habitats than to the trait values of potential colonists in the regional species pool (but see, e.g., Fox 1987; Fargione et al. 2003). Consequently, the connection between convergence in species traits and in community structure remains poorly understood. In this article, we explore this connection, using tropical trees and their association with mycorrhizal fungi as an illustrative example.

\section{Mycorrhizal Association and Forest Monodominance}

A classic case of convergent evolution in plants is their association with mycorrhizal fungi (Brundrett 2002). There are at least 19 evolutionarily independent origins of ectomycorrhizal (EM) symbiosis in plants (Koele et al. 2012) and more than 60 in fungi (Tedersoo et al. 2010). In addition, plants associated with EM fungi may potentially experience common selective pressure and, because of it, undergo further convergent evolution in other traits, particularly those related to resource economy (e.g., Read 1991; Cornelissen et al. 2001; Phillips et al. 2013; but see Koele et al. 2012).

As a result, EM host plant species may form a species alliance (sensu Van Nes and Scheffer 2004). That is, EM host plants may modify the local environment to make it more favorable to the members of their own alliance (EM plant species) than to those of other plants, which are often associated with arbuscular mycorrhizal (AM) fungi. Thus, if by chance a locality were initially dominated by EM plants, it might persist as such owing to positive feedbacks resulting from this alliance. Consequently, it is possible that local plant communities diverge as alternative stable states, each developing as either EM or AM dominated as a result of priority effects, as we explain in more detail below.

A particularly striking example of such alternative stable states is seen in the phenomenon of tree species monodominance in tropical forests, in which forests otherwise characterized by highly diverse plant communities are dotted by occasional stands in which one tree species is far more dominant than any other (Richards 1952; Janzen 1974; Connell and Lowman 1989; Hart et al. 1989; Torti et al. 2001). In tropical forests, such stands can range in area from one to several thousand hectares (Peh et al. 2011). The term "monodominance" has been variously defined in the tropical forest literature, but here we consider those cases in which one species contributes more than $60 \%$ of total basal area (Hart et al. 1989) or more than $25 \%$ of total stem density of a forest stand that is surrounded by mixed forest.

There are a number of hypothesized mechanisms by which monodominance can emerge (Torti et al. 2001; Frederickson et al. 2005; McGuire et al. 2008; Peh et al. 2011), but one factor that is frequently associated with monodominance is the mycorrhizal status of the plants (Hart et al. 1989). Tree species that host any type of mycorrhiza can form monodominant stands. For example, multiple species from primarily AM plant families (Brundrett 2009)such as the Apocynaceae, Burseraceae, Euphorbiaceae, Fabaceae, Lauraceae, Moraceae (reviewed in Peh et al. 2011), and Rubiaceae (Frederickson et al. 2005)_form monodominance. However, monodominance-forming species are disproportionately from EM lineages within the Dipterocarpaceae, Fabaceae, Fagaceae, and Juglandaceae (reviewed in Peh et al. 2011; Smith et al. 2013; Corrales et al. 2016). One defining feature of monodominant stands of EM host tree species in Neotropical rainforests is that they are embedded in forest with a more even abundance distribution of primarily AM host trees. EM host monodominance in these forests is particularly dramatic, given that far fewer tree species form EM compared with AM associations in typical mixed forest stands and that EM host species are often found at low abundances outside of the monodominant patches (Henkel 2003; Corrales et al. 2016).

The mechanisms that cause mycorrhizal status to generate monodominance are not fully understood but likely involve positive plant-soil feedback as one form of priority effects. EM monodominant stands are thought to result in part from positive feedback caused by their EM association, in which local soil conditions are made more favorable to EM than to AM host trees (Dickie et al. 2014). These changes in local soil conditions may involve the species composition of mycorrhizal fungi and other soil microbes or plant-induced nutrient depletion (Corrales et al. 2016; Peay 2016). Priority effects driven by such self-enforcing habitat modification-or niche construction (sensu Odling-Smee et al. 2003) — can lead to alternative stable states, in which EM trees may form monodominant stands when they establish earlier than other species after local disturbance but are otherwise excluded by AM trees.

Intriguingly, however, these potential instances of alternative stable states with either high-diversity AM assemblages or low-diversity EM monodominant stands are observed in only some tropical regions (e.g., South America and Africa) but not in others (e.g. Southeast Asia), where a diverse suite of AM and EM plant species codominate. To our knowledge, no study has directly addressed why this difference exists, 
yet this geographical contrast presents itself as an opportunity to gain a better understanding of how and when monodominance may arise as an alternative stable state.

\section{Natural History of Mycorrhizal Association as a Motivation for This Article}

The purpose of this article is to develop a biogeographical hypothesis to explain why EM monodominance arises in some tropical forest regions and not in others. More generally, our goal is to use monodominance as a case in point to discuss how community convergence can be influenced by trait convergence and how the extent of this effect can be mediated by the properties of the species pool.

Our motivation for this goal comes from the idea that EM monodominance may be associated with convergent values of plant traits related to resource economy, such as leaf chemistry and decomposability (Torti et al. 2001; Peh et al. 2011). Traits of EM host plant species (such as specific leaf area, leaf $\mathrm{C}$ and $\mathrm{N}$ content, and $\mathrm{C}: \mathrm{N}$ ratio) have been found to differ significantly from those of AM host plant species (Read 1991; Phillips et al. 2013), suggesting that several lineages of EM plant species may have converged and, in the process, as a functional group diverged from AM plant species in these traits. Even so, there can still be substantial trait variation across plant species within the EM group (Koele et al. 2012), which may affect the strength and direction of plant-soil feedbacks. For example, interspecific variation in leaf $\mathrm{C}: \mathrm{N}$ ratios may increase the variation in the strength and direction of plant-soil feedbacks among EM species (Ke et al. 2015).

In this article, we seek to link the possibility that interspecific trait variation is associated with variation in plantsoil feedbacks with one aspect of forest communities that is highly variable among tropical regions: the size of the local pool of tree species that host EM fungi (Peay 2016). This size ranges from only a few species in South America (e.g., Baraloto et al. 2011) to hundreds in Southeast Asia (e.g., Brearley 2012). We focus on this difference among regions in species pool size and the associated potential variation in the strength of species interactions mediated by plant-soil feedbacks. We hypothesize that a diverse EM species pool and the resulting complexity in local interactions among EM species makes trait convergence in these species difficult and that this obstacle to trait convergence in turn prevents the strong divergence of local communities that is necessary for the emergence of monodominant patches.

To develop this hypothesis, we use results from computer simulation of plant community assembly. The simulation model is not intended to replicate actual community assembly to quantitatively predict community patterns, but instead to explore possible qualitative outcomes arising from a small set of assumptions that characterize species interactions me- diated by plant-soil feedbacks. We also examine whether empirical leaf functional trait data are consistent with the hypothesis developed with our model. Variation in leaf functional traits reflects selection for ecological strategies of resource acquisition and conservation (Donovan et al. 2011; Reich 2014) and is correlated with mycorrhizal status (Read 1991; Phillips et al. 2013). The leaf data we use for this purpose are from two typical mixed forests in different geographic regions. One is from a Neotropical forest in the Peruvian Amazon, where EM plants are rare and the EM plant species pool is small. The other is from a Paleotropical forest in Borneo, where EM plants are common and the EM plant species pool is large.

\section{Simulation Methods \\ Overview}

The simulation model we used is a modified version of $\mathrm{Fu}$ kami and Nakajima's (2013) individual-based, spatially implicit model of plant community assembly through stochastic sequential immigration of species from an external species pool. In this model, which is built on traditional plant competition models (Chesson 1985; Pacala and Tilman 1994; Mouquet et al. 2002; Fukami and Nakajima 2011), plant individuals compete for local resources during the individual establishment stage. They also affect one another's competitiveness via plant-soil feedback. We assume that plants can take on one of two mycorrhizal associations, EM or AM. There are other potential mycorrhizal states (e.g., nonmycorrhizal or ericoid mycorrhizal), but EM and AM associations represent most tree species and individuals in tropical forests (McGuire et al. 2008; Brundrett 2009). We also assume that plants that host both EM and AM fungi can be considered primarily EM associated, because the root systems of these plants tend to become dominated by EM fungi (Egerton-Warburton and Allen 2001).

We vary the size of the EM host species pool (the number of EM host species) while holding constant the number of AM species in the pool, and we examine how the size of the EM species pool influences the way local plant communities assemble, particularly with respect to the emergence of the alternative stable state of EM monodominance. By replicating community assembly in many local forest patches with the same species pool, we examine how species abundance distributions may vary among patches that have the same set of local abiotic conditions within them but differ in the history of stochastic species arrival. In particular, we assess the conditions under which the local abundance of EM hosts shows strong bimodality, in which a single EM host species becomes monodominant in some local patches but remains rare or absent in all other patches.

As in Fukami and Nakajima's (2013) model, plant recruitment occurs in sites that are arranged in a patch. Plants 
are recruited from both seeds produced by established individuals within the patch and immigration from an external species pool. For immigration, species of plants were randomly chosen for immigration each time step from the species pool. The chosen species immigrated as a small number of propagules to a local forest patch consisting of 1,000 recruitment sites. One thousand recruitment sites roughly correspond to the sapling abundance we may expect in a hectare, the scale at which small monodominant stands are observed. All recruitment sites were initially empty. Subsequently, only one plant individual could establish and produce propagules in each recruitment site, even when multiple propagules arrived from the species pool or from local dispersal within the patch. Propagules were distributed randomly to recruitment sites within the patch each time step. Of the propagules that arrived at a recruitment site, the one that belonged to the species that best fit the environmental condition of the recruitment site could establish and produce propagules (determination of environmental fit is described in more detail below). All plants within a patch produced propagules once each time step (e.g., each year or each mast event) until they died. All plants died with a fixed probability, and when they did, recruitment sites became empty and available for a new plant individual to establish. Real tree species vary in dispersal ability, fecundity, and mortality rates, but we kept these constant across species to focus on the mechanisms of monodominance in relation to our hypothesis. This process of immigration, arrival, establishment, reproduction, and death was repeated for 400 time steps. All simulations were carried out using Mathematica 8.0 (Wolfram Research, Champaign, IL). Code and data are available as supplementary material, available online. ${ }^{1}$

\section{Species Pools}

Regional species pools each contained 100 AM plant species and one to 20 EM plant species. Each species $i$ was defined by a value $R_{i}$, which can be thought of as a multitrait phenotype that determines how well species perform in local abiotic conditions during the recruitment stage (see details below). Values of $R_{i}$ were chosen randomly between 0 and 1 from a beta distribution, where the probability density for value $x$ was proportional to $x^{a-1}(1-x)^{b-1}$ (Mouquet et al. 2002). We set $a=b$, which causes the probability density for $R_{i}$ to have a peak at 0.5 , but the value of $a$ was varied in order to examine the effect that the amount of variation in $R_{i}$ among species had on community assembly. We refer to $1 / a$ as interspecific phenotypic variability $v$. A larger $v$ means that $R_{i}$ values are more variable among species (fig. $1 B$ ). In addition to $R_{i}$, species were also characterized

1. Code that appears in the American Naturalist is provided as a convenience to the readers. It has not necessarily been tested as part of the peer review. by a set of values $\left(S_{i j}\right)$ that defined the strength of plant-soil feedback, in which the presence of a plant individual belonging to species $j$ at a recruitment site during a given time step changed the competitive ability of a plant belonging to species $i$ at that recruitment site during the following time step (see details below).

\section{Local Patches}

Local forest patches each consisted of 1,000 recruitment sites. Each recruitment site could accommodate only one adult tree and was characterized by a value that represents abiotic conditions $\left(H_{k}\right)$, chosen randomly between 0 and 1 from a beta distribution. For the beta distribution for $H_{k}$, we set $a=b=2$, which — as with the case of $R_{i}$ - produces a

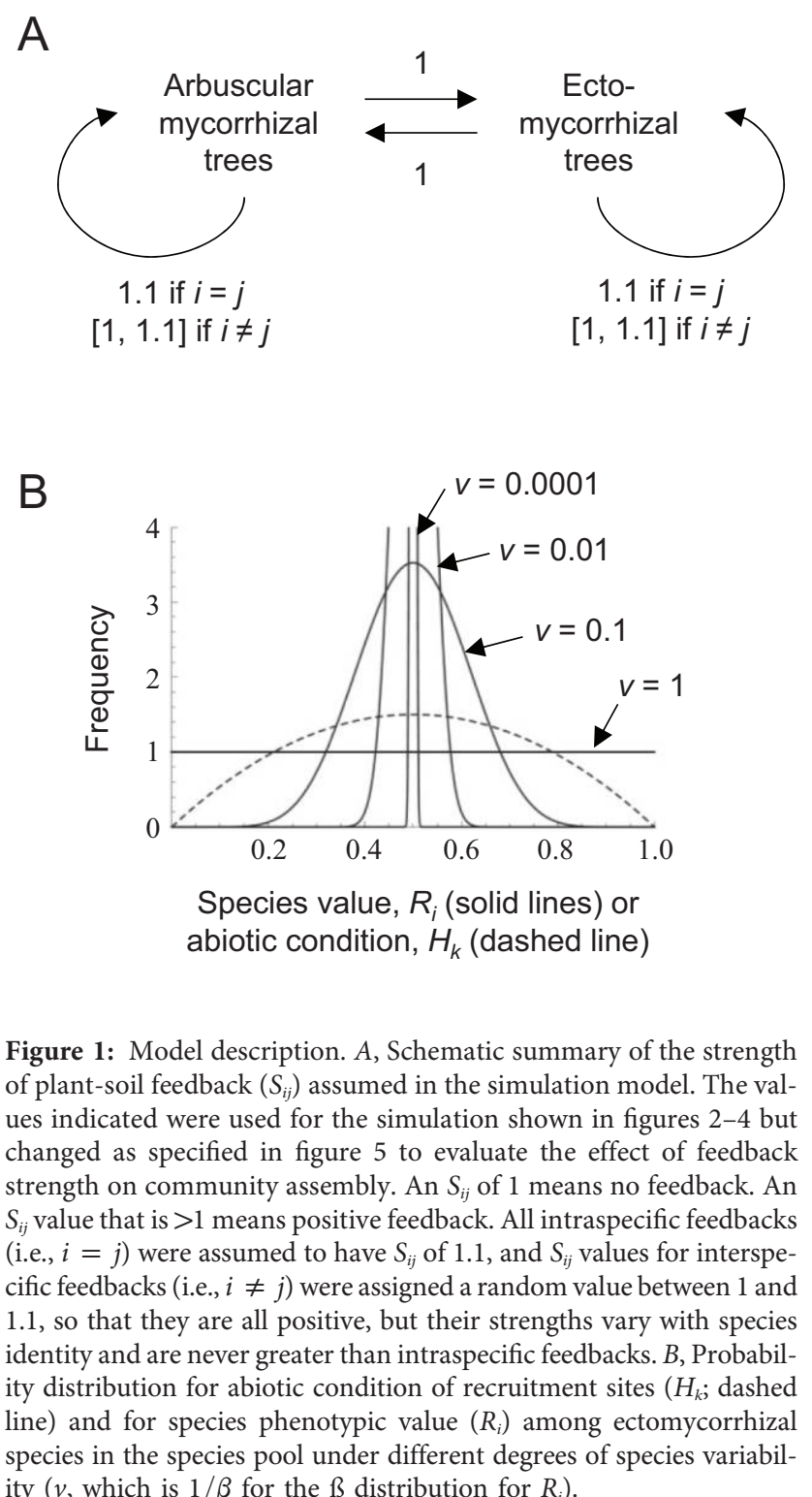

A
1.1 if $i=j$

$[1,1.1]$ if $i \neq j$

Species value, $R_{i}$ (solid lines) or abiotic condition, $H_{k}$ (dashed line)
Figure 1: Model description. A, Schematic summary of the strength of plant-soil feedback $\left(S_{i j}\right)$ assumed in the simulation model. The values indicated were used for the simulation shown in figures 2-4 bu changed as specified in figure 5 to evaluate the effect of feedback strength on community assembly. An $S_{i j}$ of 1 means no feedback. An $S_{i j}$ value that is $>1$ means positive feedback. All intraspecific feedbacks (i.e., $i=j$ ) were assumed to have $S_{i j}$ of 1.1 , and $S_{i j}$ values for interspecific feedbacks (i.e., $i \neq j$ ) were assigned a random value between 1 and 1.1, so that they are all positive, but their strengths vary with specie identity and are never greater than intraspecific feedbacks. $B$, Probability distribution for abiotic condition of recruitment sites $\left(H_{k}\right.$; dashed species in the species pool under different degrees of species variabil ity $\left(v\right.$, which is $1 / \beta$ for the $\beta$ distribution for $R_{i}$ ). 
peak of $H_{k}$ values at 0.5 (fig. $1 B$ ). For all simulations in a run, the $H_{k}$ values remained the same.

\section{Competitive Ability}

Values of $H_{k}, R_{i}$, and $S_{i j}$ together determined competitive ability $\left(C_{i j k}\right)$ of species $i$ at recruitment site $k$ when the recruitment site was occupied by species $j$ at the previous time step:

$$
C_{i j k}=\left(1-\left|H_{k}-R_{i}\right|\right) S_{i j} \text {. }
$$

Thus, assuming that $S_{i j}=1$ (i.e., no effect of species $j$ and species $i$ through plant-soil feedback, as explained below), a species would have a high value of $C_{i j k}$ if it had a value of $R_{i}$ that is close to that of $H_{k}$, as in Mouquet et al.'s (2002) model. In our simulation, a close match between $H_{k}$ and $R_{i}$ is most likely when a species' $R_{i}$ value is 0.5 , since $H_{k}$ also has a peak at 0.5 (fig. $1 B$ ).

Plant-soil feedback moderates competitive ability, with the value of $S_{i j}$ defining the direction and strength of the feedback. Specifically, $S_{i j}$ defines the effect of species $j$ occupying a given recruitment site during a given time step on the competitive ability of species $i$ in that microsite during the following time step. Thus, $S_{i j}$ affects the competitive ability of species $i$ independently of both recruitment site condition (as defined by $H_{k}$ ) and species phenotype (as defined by $R_{i}$ ) and represents the amount by which the difference between the abiotic environment and the species' match to the environment is improved $\left(S_{i j}>1\right)$, worsened $\left(S_{i j}<1\right)$, or not affected $\left(S_{i j}=1\right)$ via plant-soil feedback (Fukami and Nakajima 2013). That is, if $S_{i j}=1$, there is no net effect of plant-soil feedback, whereas $S_{i j}>1$ and $S_{i j}<1$ represent positive and negative plant-soil feedback, respectively.

We set the values of $S_{i j}$ to attempt to represent the interactions within and between AM and EM plants that are observed in nature (fig. $1 A$ ). There are many ways in which plant-soil feedback could be structured, but here we assume that plants facilitated the growth of conspecific individuals via local accumulation of specific mycorrhizal fungi that are beneficial to them, via modification of soil nutrient composition to the species' own benefit via their specific mycorrhizal association (Corrales et al. 2016) or via better protection from pathogens through added physical or chemical defenses in mycorrhizal roots (Duchesne et al. 1989; Newsham et al. 1995; Bennett et al. 2017). Plants can also negatively affect conspecifics by, for example, accumulating soil pathogens (Kulmatiski et al. 2008). However, studies that examine net effects of pathogens plus mycorrhizae often find overall positive effects from soil biota (e.g., fig. $1 B$ in Mangan et al. 2010; see also Cortois et al. 2016; Bennett et al. 2017;
Teste et al. 2017). Similarly, in a large analysis of forest plots in North America and New Zealand, Dickie et al. (2014) found that most tree species exhibited positive density dependence. We therefore assumed in our model that positive effects outweigh negative ones to result in net positive plantsoil feedback for conspecifics. Accordingly, we set $S_{i j}=1.1$ when $i=j$.

We also assumed that EM tree species shared similar nitrogen economy (Corrales et al. 2016) as well as similar associations with EM fungi. As a result, EM plant species can benefit each other to some extent, but the strength of interspecific plant-soil feedback is variable among EM plant species pairs and is never greater than that of intraspecific feedback. We believe that these assumptions are plausible because evidence suggests that EM fungi tend to be generalists with high overlap between co-occurring species (Kennedy et al. 2003; Peay et al. 2015; but see Bennett et al. 2017) and that shared EM fungi can facilitate interspecific recruitment (Horton et al. 1999; Nara 2006b). In addition, there is evidence that different combinations of EM fungi and plants can have different effects on plant growth, even among closely related species (Nara 2006a; Fransson et al. 2015). Consequently, when $i \neq j$, we assigned $S_{i j}$ values by taking a uniform randomly drawn value between 1 and 1.1 for each $S_{i j}$. For simplicity, we assume that this same pattern of intraand interspecific feedback strengths also holds for AM plant species. In other words, EM and AM host species have similar capacities for positive plant-soil feedback in our model. Finally, we also assumed that EM and AM plant species did not facilitate each other through plant-soil feedback. Thus, $S_{i j}=1$ between all pairs of an EM species and an AM species.

The direction and strength of plant-soil feedback in tropical forests have not been thoroughly characterized, and it is uncertain whether the assumptions specified above are always realistic. To examine whether model results are sensitive to these assumptions, we ran two sets of additional simulation. In the first, we assumed that among EM host plants, $S_{i j}$ took a uniform randomly drawn value between 1 and 1.1, even when $i=j$, in order to relax the assumption that all intraspecific feedbacks were more or equally positive compared with any interspecific feedbacks (fig. S1B; figs. S1S5 are available online). In a second set, we used a combination of alternative assumptions. Specifically, we assumed (1) variable positive intra- and interspecific feedbacks for EM host plants, (2) variable intra- and interspecific feedbacks (both positive and negative) for AM host plants, and (3) negative effects of EM host plants on AM host plants. For assumption 1 , we tried two variants. In one (variant 1 ), we used the original assumption as above, that is, that the strength of interspecific plant-soil feedback is variable among EM plant species pairs and is never greater than that of intraspecific feedback (fig. S1C). The other (variant 2) is that interspecific and intraspecific feedbacks are all positive but 
equally variable, such that some intraspecific feedbacks are less positive than some interspecific feedbacks (fig. S1D).

\section{Community Assembly}

At each time step, each species in the species pool immigrated to the local patch with probability $I$. For each of the $100 \mathrm{AM}$ species in the pool, we used $I=0.05$. For each EM species, we used $I=1 /$ (number of EM species in the pool). For example, when we had two or 20 EM species in the pool, $I$ was 0.5 or 0.05 for each EM species, respectively. This way, we standardized for the total immigration frequency for all EM plants across the gradient of the size of the EM species pool. We also did additional simulation in which $I=$ 0.05 for each species, regardless of the size of the EM species pool used, in order to decouple the effects of regional species richness per se from those of regional relative abundance.

At each recruitment site in the local patch, species $i$ arrived with probability $1-\exp \left[-\left(P_{i}+F N_{i}\right) /\right.$ (total number of recruitment sites, i.e., 1,000)] at each time step. Here, $P_{i}$ is the number of propagules of species $i$ that immigrate from the species pool (20 propagules for species chosen for that time step for immigration from the species pool, and 0 seed for all other species), $F$ is fecundity (50 for all species), and $N_{i}$ is the number of plants belonging to species $i$ in the local patch ( 0 for all species in the first time step, i.e., at $t=1$, which is analogous to modeling recruitment after a stand-replacing disturbance). The specifications were chosen so as to have values that likely fall within a plausible range. When the number of recruitment sites that were assigned to receive a propagule of species $i$ exceeded $P_{i}+F N_{i}$ (which rarely happens), $P_{i}+F N_{i}$ recruitment sites were randomly selected from these recruitment sites, and a propagule of the species were assigned only to the selected recruitment sites.

Given this probability, there were three possibilities regarding plant establishment and seed production in each recruitment site. First, if the recruitment site were already occupied by a plant, that plant remained there. In other words, we assumed that seeds could not displace established adults. Second, if the recruitment site were empty and no species arrived at that recruitment site, it remained empty. Third, if the recruitment site were empty and one or more species arrived at that recruitment site, of those species that arrived, the one with the greatest value of $C_{i j k}$ (independent of the number of propagules of each species) was assumed to occupy the recruitment site and produce propagules starting the following time step. The seed-to-adult recruitment processes are important in many of the dynamics modeled here, but processes operating during those stages per se were not the focus of our model, which was intended to identify the minimal processes required to produce monodominance.
After plant establishment was completed for all recruitment sites, plants occupying a recruitment site died with probability $m$, which was 0.4 for all species. Thus, competitive ability in our model is not related to dispersal, fecundity, or baseline survival; it dictates only a species' ability to win a recruitment site. We assembled communities for 400 time steps. From visual inspection of results, 400 time steps seemed long enough for most communities to reach an equilibrium state (fig. 2).

\section{Manipulating Species Pool Size and Species Variability}

We manipulated two factors - the number of EM species in the species pool and the amount of variation in $R_{i}$ among

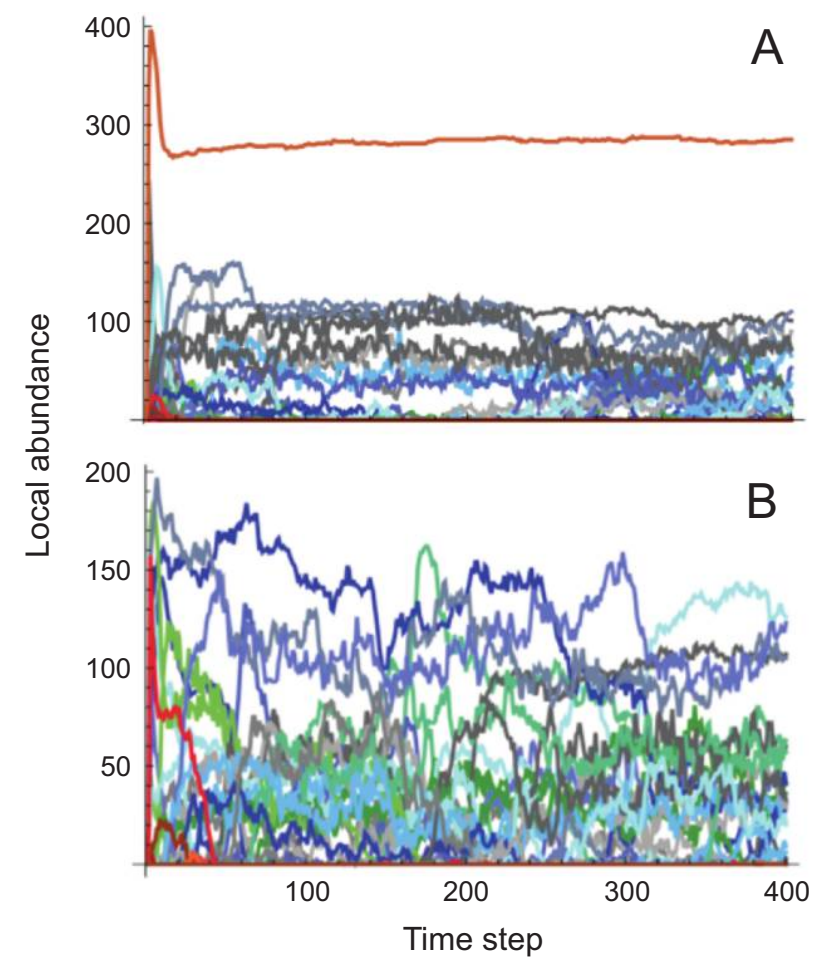

Figure 2: Examples of simulated population dynamics for two forest patches, showing ectomycorrhizal $(\mathrm{EM})$ monodominance $(A)$ and arbuscular mycorrhizal (AM) dominance $(B)$ as alternative stable states. Both $A$ and $B$ show results for one instance of local community assembly under the same species spool, and each line indicates a species, with warm colors denoting EM tree species and cold colors denoting AM tree species. In these examples, there were $100 \mathrm{AM}$ tree species and $10 \mathrm{EM}$ tree species in the species pool, and species variability among EM species $(v)$ was set to be small $(v=0.0001)$, with all EM species having an $R_{i}$ value very close to the optimal, 0.5 (see fig. $1 B$ ). Depending on assembly history, local communities develop either as EM monodominance $(A)$, in which a single EM species becomes dominant (orange line) and all others are AM species, or as an AM-only community (B), in which a few EM species were able to colonize the forest patch initially but became locally extinct because they were not common initially and were excluded competitively by AM species through positive plant-soil feedback among AM species. 
EM host species (i.e., species variability $v$, as defined in "Species Pools") - to examine their effects on EM abundance in assembled local communities. To this end, under each of the species pools we used (i.e., 16 pools in fig. 3), we ran the simulation 100 times, with each run considered one instance of community assembly in a local forest patch. Under each species pool, the replicated 100 patches had the same set of recruitment sites, which allowed us to evaluate whether plant communities that develop in different patches that share the same set of $H_{k}$ values in them diverged in species composition as a result of random variation in the history of species arrival from the species pool. If they did diverge, that would be evidence for alternative stable states. We were particularly interested in assessing the conditions under which EM monodominance arose. We defined EM monodominance as the case in which only one dominant EM species occupied one-fourth (25\%) or more of the available recruitment sites in a patch, with the other sites being occupied by AM species.

\section{Simulation Results and Discussion}

Simulation results verified that communities with (fig. $2 A$ ) and without (fig. $2 B$ ) monodominant EM species could develop as alternative stable states in our model. Under the same species pool, communities were either dominated by AM species without any EM species present or had at least 25\% EM individuals, representing two alternative stable states, similar to those seen in some Neotropical rainforests.

By varying species pool size and phenotypic variability (fig. 3), we found that EM monodominance arose as an alternative state whenever trait variability among EM species was low. In these cases, all EM species in the species pool had an $R_{i}$ value that was nearly optimal for the abiotic conditions available in the forest patch. Under this condition, a single dominant EM species was competitive enough to form monodominant stands when it arrived early duringlocal community assembly but not when it arrived late, as indicated by the strongly bimodal pattern in the top row in figure 3. One of the two modes had no EM species, and the other mode had only one EM species, even when the species pool contained multiple EM species.

Regardless of species pool size, as $R_{i}$ values became more variable among EM species in the local species pool (i.e., moving from top to bottom rows in fig. 3), the EM total abundance became more variable among forest patches, and the bimodal pattern became increasingly obscure. The frequency of monodominance declined with greater phenotypic variability when there was more than one EM species in the pool because, although the number of EM trees in a patch might be high, these patches consisted of multiple EM species.

The additional simulation indicated that these results generally held under the alternative assumptions examined, but only when all intraspecific feedbacks were more or equally positive compared with interspecific feedbacks (fig. S1C). Otherwise, multiple EM plant species often coexisted as a result of mutual facilitation among them, with only a small number of monodominance patches developing (fig. S1B, $\mathrm{S} 1 D)$. Therefore, one condition for monodominance formation in our model is stronger positive intraspecific relative to interspecific feedback among EM trees, which is consistent with some recent empirical data (Bennett et al. 2017). Strong intraspecific feedback is possible if, for example, a tree species cultivates an assemblage of highly beneficial EM fungi. The additional simulation in which immigration rate $I$ was 0.05 , regardless of the size of the EM species pool, indicated that the number of monodominant patches is positively correlated with the immigration rate per EM species (fig. S2A, S2C).

Together, these results suggest that there is no effect of species pool size per se on whether EM monodominance will emerge or on how strong the bimodal pattern reflecting monodominance formation will be. Rather, it is the amount of phenotypic variability among EM species that shapes the pattern of EM abundance in local patches. Specifically, reduced variability tends to cause greater frequency of monodominance (fig. 3). In order to directly test for the relationship between species pool size and phenotypic variability of EM species, we ran additional simulations to examine how species pool size influences the relationship between species phenotypic value $\left(R_{i}\right)$ and the abundance of EM species when EM species variability in the species pool is large $(v=1)$. We found that when species pool size was small, there was a relatively good correspondence between $R_{i}$ value and EM species abundance (fig. $4 A$ ). We call this correspondence trait-environment matching, meaning that the closer species are in their phenotype $R_{i}$ to the optimal (i.e., 0.5 in our simulation), the more abundant they tend to become. In this case, the abundances of species follow what is expected on the basis of their match to the environment (i.e., $\left|R_{i}-H_{k}\right|$ ).

As species pool size was increased, this correspondence became weaker (fig. 4), such that species with an optimal $R_{i}$ value (closer to 0.5 ) were not necessarily more abundant than those with a suboptimal value (away from 0.5 ). When the species pool was diverse, two additional abundance peaks appeared (at $R_{i}$ of around 0.2 and 0.8 ), so that species that did not have an $R_{i}$ close to 0.5 could nevertheless be as abundant as those with an optimal $R_{i}$, as most clearly seen in figure $4 D$. In short, for EM species in our model, it is adaptive to have traits that best match the underlying abiotic environmental conditions if there are not many EM species in the species pool. However, if the species pool has many EM species, our results suggest that there can be disruptive natural selection that keeps some species away from having the abiotically optimal $R_{i}$ value if the species pool has many species. As a 


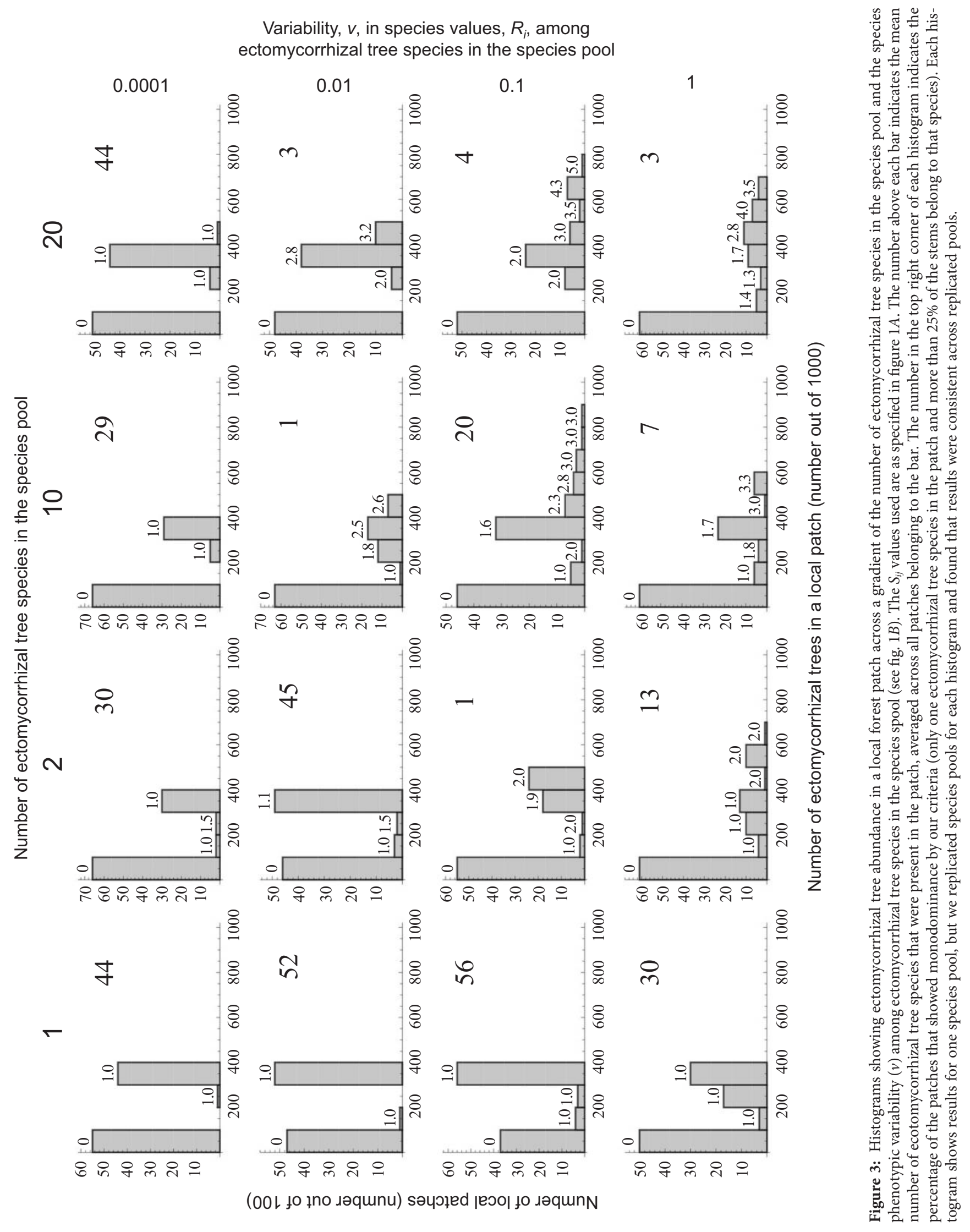


Number of ectomycorrhizal tree species in the species pool

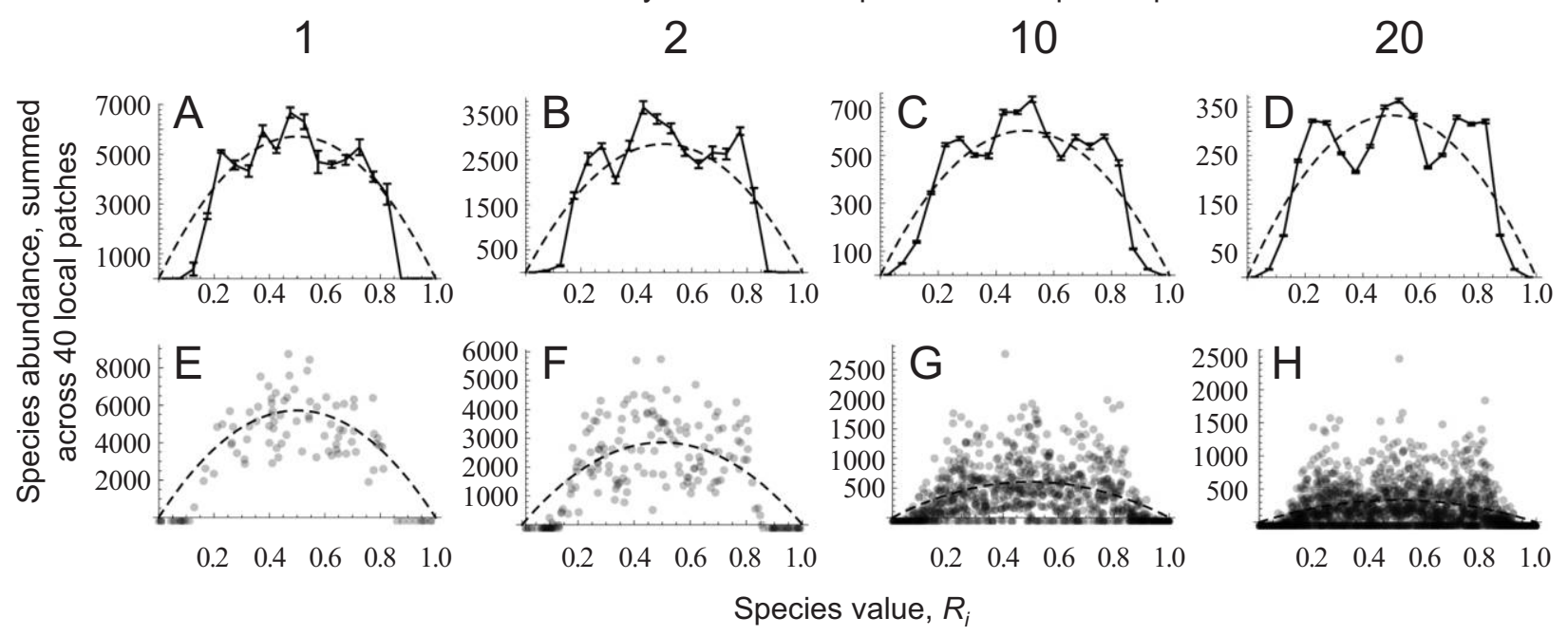

Figure 4: Relationship between species value $\left(R_{i}\right)$ and the abundance of ectomycorrhizal tree species across a gradient of the number of ectomycorrhizal tree species in the species pool. $A-D$, Results for a total of 2,400 community assembly outcomes comprising 100 replicated species pools, under each of which 40 replicated local communities were assembled. The $Y$-axis is the mean abundance of a species in a local community, averaged across the 40 replicated local communities, which were then averaged across species having similar $R_{i}$ values (with error bars showing standard errors). Solid lines are the simulation results, and dotted lines show the relationship that would be expected if abundance were determined solely by availability of recruitment sites (i.e., the frequency of recruitment sites having specific values of $H_{k}$, abiotic condition of microsite). $E-H$, Results based on the same data as for $A-D$, but instead of showing mean abundances and standard errors, the abundance of each species is indicated (each circle represents a species).

result, convergent trait evolution that results in low interspecific trait variability and tight trait-environment matching in the species pool may be more likely when the EM species pool is small, whereas divergent trait evolution may arise when the EM species pool is large.

Why do EM species with suboptimal phenotypes obtain comparable densities to those with optimal phenotypes when the species pool is large (fig. $4 D$ )? We suspected that it was because the abundance of each EM species is affected so strongly by the plant-soil feedback - which is made more complex by the larger number of EM species that each have different strengths of plant-soil feedback-that the underlying influence of abiotic conditions is overwhelmed and obscured. To test this idea, we reran the simulation, but this time with the strength of plant-soil feedback among EM and/or AM species $\left(S_{i j}\right)$ all set to 1.1 instead of being drawn uniform-randomly from $[1,1.1]$. Setting all $S_{i j}$ values to 1.1 makes interspecific feedback strengths all the same and equal to intraspecific feedback strength, eliminating the complexity of feedback strength. In this additional simulation, we found good trait-environment matching - such as the one seen under small species pools (fig. 4A) - if all $S_{i j}$ values among EM species were set to 1.1 (fig. $5 B$ ). Poor trait-environment matching was not, however, eliminated when $S_{i j}$ values among AM species were set to 1.1 (fig. $5 C$,
$5 D)$. These results support our hypothesis that it is the variation in interspecific feedback strengths among EM species that makes trait-environment matching poor and monodominance unlikely when the species pool is large.

In summary, our results suggest that two interdependent processes influence the likelihood of trait and community convergence. First, trait-environment matching that leads to trait convergence among EM species may be less likely under a larger EM species pool because of local plant-soil feedbacks that vary in strength. Second, weak trait convergence may in turn impede the development of EM monodominance, which represents an extreme case of community divergence.

\section{Empirical Trait Data Analysis \\ Study Systems and Methods}

To begin to assess whether empirical data are consistent with the hypothesis developed with the model above, we analyzed leaf trait data from trees in two geographic regions: Southeast Asia (Borneo), where EM trees are common in most lowland forests, and South America (Peruvian Amazon), where EM trees are generally rare but can become monodominant. Both regions contain large areas of lowland tropical rainforests with extraordinary levels of tree di- 
Strengths of inter-specific feedback in EM trees

$[1,1.1]$
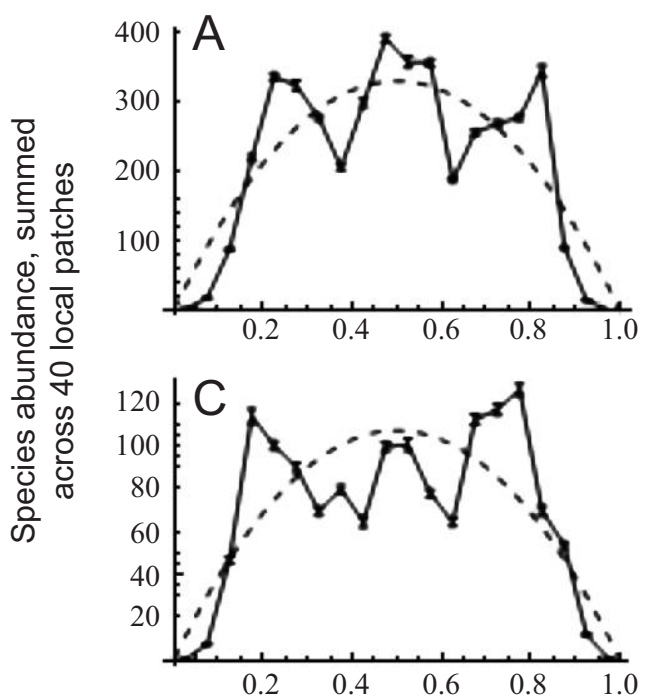

All 1.1
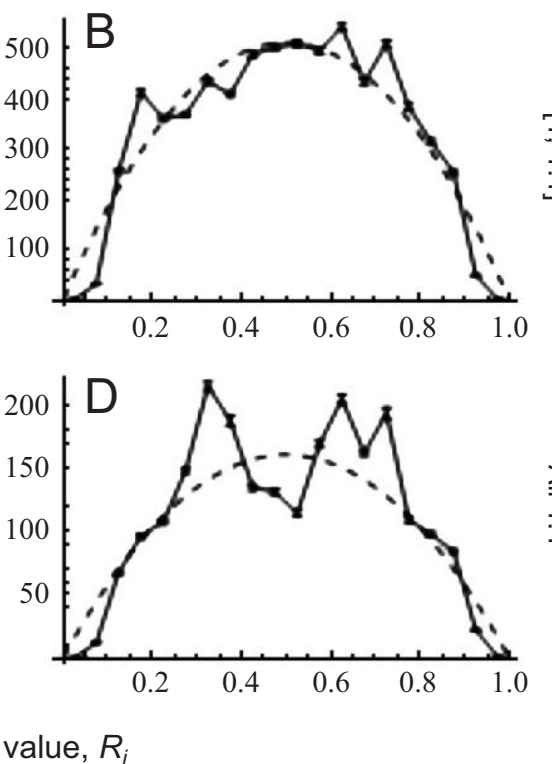

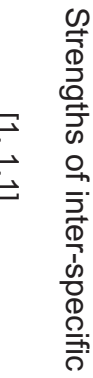

Species value, $R_{i}$

Figure 5: Effect of changing $S_{i j}$ values on the relationship between species value $\left(R_{i}\right)$ and species abundance. Symbols are as in figure 4, except that data for each panel are based on 60 (not 100) replicate species pools. EM, ectomycorrhizal; AM, arbuscular mycorrhizal.

versity. The Peruvian Amazon has greater regional tree diversity (approximately 5,000 species; Pennington et al. 2004) than Borneo (approximately 3,000 species) probably because it is connected to the rest of the Amazon basin, the world's largest contiguous area covered by lowland rainforest. Thus, at the scale of a local patch of forest (e.g., Lambir Hills in Borneo or Allpahuayo-Mishana in Peru), we expect the regional tree species pool to be reasonably similar, with Peru being slightly larger. However, the pool of EM trees is much larger in Borneo than in Peru.

For our analysis, trait data were taken from two separate studies of plant functional ecology in Peruvian Amazon (Fortunel et al. 2012, 2014) and Borneo (Russo et al. 2005, 2013). Detailed methods on data collection can be found from Fortunel et al. $(2012,2014)$ and in the appendix, respectively. Data in Peru were collected from multiple 0.5-ha Gentry plots, whereas those in Borneo were collected from within a single 52-ha forest dynamics plot in Lambir Hills National Park. We used data on four leaf traits that are involved in the fast-slow plant economics spectrum (Reich 2014) and that are thought to be strongly filtered by environmental conditions (Fortunel et al. 2014): specific leaf area (SLA), leaf carbon and nitrogen concentrations by mass, and leaf $\mathrm{C}: \mathrm{N}$ ratio. Leaf $\mathrm{C}: \mathrm{N}$ ratio is considered a particularly important trait in determining the strength of plant-soil feedbacks (De Deyn et al. 2008; Ke et al. 2015). Data from individual plants were averaged within species. Species' mycorrhizal status was classified at the genus or family level on the basis of Brundrett (2009) and Peay et al. (2013). Data are deposited in the Dryad Digital Repository: http://dx.doi.org/10.5061/dryad .c0kr7 (Fukami et al. 2017).

For each region, we analyzed trait data from lower fertility (sand) and higher fertility (clay) soil habitats separately because these habitats differ in species pool composition within each region. The trait data set from Peru included 365 AM and 13 EM species from clay soils and 140 AM and 3 EM species from sandy soils. The trait data set from Borneo included $98 \mathrm{AM}$ and 17 EM species from clay soils and $111 \mathrm{AM}$ and $35 \mathrm{EM}$ species from sandy soils. We took three approaches to look for differences in EM traits between the two species pools (Peru and Borneo) within soil types. First, we compared mean trait values for EM versus AM host species within each species pool, using a twosample $t$-test, to evaluate our prediction that EM species are functionally distinct from AM species. Second, we compared the variance of trait values for EM versus AM species within each species pool, using a one-sided variance ratio F-test, to evaluate our prediction that EM species have larger trait variability than AM species. Third, we compared the variance in trait values between EM species pools in Borneo and Peru, using a one-sided variance ratio F-test, to evaluate our prediction that there should be greater variation in trait values among EM host species in Borneo than in Peru, where EM monodominance is found. We do not approach 
this question in an explicit phylogenetic framework, but our test is conservative because we predict larger trait variation in the narrower phylogenetic pool, that is, in Borneo, which had only one EM family (Dipterocarpaceae).

\section{Trait Analysis Results and Discussion}

We found significant differences in some mean foliar trait values between AM and EM species in both Peru and Borneo that were consistent with our model prediction (table 1; fig. 6). In Peru, foliar $C: N$ ratio was significantly different between AM and EM species on both soil habitats, and foliar nitrogen concentration was different only on clay soil. In Borneo, foliar carbon concentration differed significantly between AM and EM species on both habitats, but no other significant differences were observed. The difference found in Peru between AM and EM host species in foliar $\mathrm{C}: \mathrm{N}$ was particularly large, in contrast to virtually identical means for this trait in Borneo (fig. 6).

One possible explanation for these inconsistencies lies in the relative differences in the sizes of EM and AM host species pools in each forest. To the extent that greater richness of the species pool causes more complex plant-soil feedbacks within each mycorrhizal group, in Peru (with fewer EM host species), their traits may track environmental conditions closely, causing a large divergence from those of AM host species. Since the pool of AM species is larger, they may be influenced strongly by the complex plant-soil feedbacks, reducing their match to underlying abiotic conditions. In contrast, in Borneo, where both mycorrhizal groups are species rich, complex plant-soil interactions might have prevented species traits from tracking the environment in both EM and AM host species.

Another explanation lies in the difference in the relative soil fertility of these regions. Averaging over soil types and mycorrhizal status, foliar $\mathrm{N}$ was significantly lower $\left(F_{1,781}=\right.$ 133.7, $P<.001)$ and $\mathrm{C}: \mathrm{N}$ significantly higher $\left(F_{1,781}=\right.$ 109.8, $P<.001)$ in Borneo than in Peru, and both soils at the Bornean site are particularly low in soil $\mathrm{N}, \mathrm{P}, \mathrm{K}$, and other nutrients (Baillie et al. 2006). Low soil fertility is strongly associated with overall low foliar nutrient concentrations and higher C: $\mathrm{N}$ ratios (Chapin et al. 1993), which could give less latitude for differences between AM and EM host species in Borneo compared with more fertile sites. Trait differences between AM and EM host species in Borneo may be more tightly linked to leaf structure and physical defense, as suggested by the significant differences between mycorrhizal groups in foliar C, which is likely to affect leaf litter decomposition and, in turn, the strength of plant-soil feedbacks and the extent of trait-environment matching.

There were significant differences in the variance of leaf traits between EM and AM host species in Peru and Borneo. However, in contrast to our expectations, variance in traits was often larger for AM than EM host species in Borneo (three of four traits), whereas no significant differences were observed in trait variances between AM and EM host species in Peru (table 2). Furthermore, results for trait variance of EM species pools did not support our model prediction either. The variance in species traits was not larger among EM host species in Borneo than in Peru for any of the traits measured for clay (SLA $F_{16,12}=0.56, P=.86$; leaf carbon concentration [LCC] $F_{16,12}=0.52, P=.89$; leaf nitrogen concentration [LNC] $F_{16,12}=0.05, P=1 ; \mathrm{C}: \mathrm{N}$ $F_{16,12}=0.87, P=.61$ ) or sandy (SLA $F_{34,2}=2.32, P=$ .35 ; LCC $F_{34,2}=5.13, P=.18$; LNC $F_{34,2}=0.03, P=1$; $\left.\mathrm{C}: \mathrm{N}_{34,2}=0.49, P=.85\right)$ habitats.

How could these apparent discrepancies between model predictions and empirical patterns be reconciled? Our focus in this article has been on contrasting alternative stable states between diverse AM and monodominant EM patches, but as a family, the Dipterocarpaceae dominate this and many other forests in Southeast Asia in terms of basal area. One potential explanation for their trait convergence may then be that phylogenetic relatedness of dipterocarp species have caused them to act as if they belonged to one species, thereby allowing for trait-environment matching in the absence of complex interspecific plant-soil feedback. As for the apparent lack of trait convergence among EM relative

Table 1: Difference in species' mean values of leaf traits between arbuscular mycorrhizal (AM) and ectomycorrhizal (EM) tree species across two edaphic habitats in Peru and Borneo

\begin{tabular}{|c|c|c|c|c|c|c|c|c|c|c|}
\hline \multirow[b]{2}{*}{ Region and habitat } & \multicolumn{2}{|c|}{ No. species } & \multicolumn{2}{|c|}{ SLA } & \multicolumn{2}{|c|}{ LCC } & \multicolumn{2}{|c|}{ LNC } & \multicolumn{2}{|c|}{$\mathrm{C}: \mathrm{N}$} \\
\hline & $\mathrm{AM}$ & EM & $t$ & $P$ & $t$ & $P$ & $t$ & $P$ & $t$ & $P$ \\
\hline \multicolumn{11}{|l|}{ Peru: } \\
\hline Clay & 362 & 13 & .06 & .95 & 1.59 & .14 & -4.18 & $.001^{*}$ & 6.15 & $<.001^{*}$ \\
\hline Sand & 140 & 3 & .97 & .41 & -.15 & .89 & -2.87 & .10 & 4.68 & $.03^{*}$ \\
\hline \multicolumn{11}{|l|}{ Borneo: } \\
\hline Clay & 98 & 17 & .98 & .34 & -4.43 & $<.001^{*}$ & 1.06 & .29 & -1.34 & .19 \\
\hline Sand & 111 & 35 & 1.29 & .20 & -4.55 & $<.001^{*}$ & .58 & .56 & -.56 & .58 \\
\hline
\end{tabular}

Note: SLA, specific leaf area; LCC, leaf carbon concentration; LNC, leaf nitrogen concentration; C:N, leaf C:N ratio.

${ }^{*} P<.05$. 

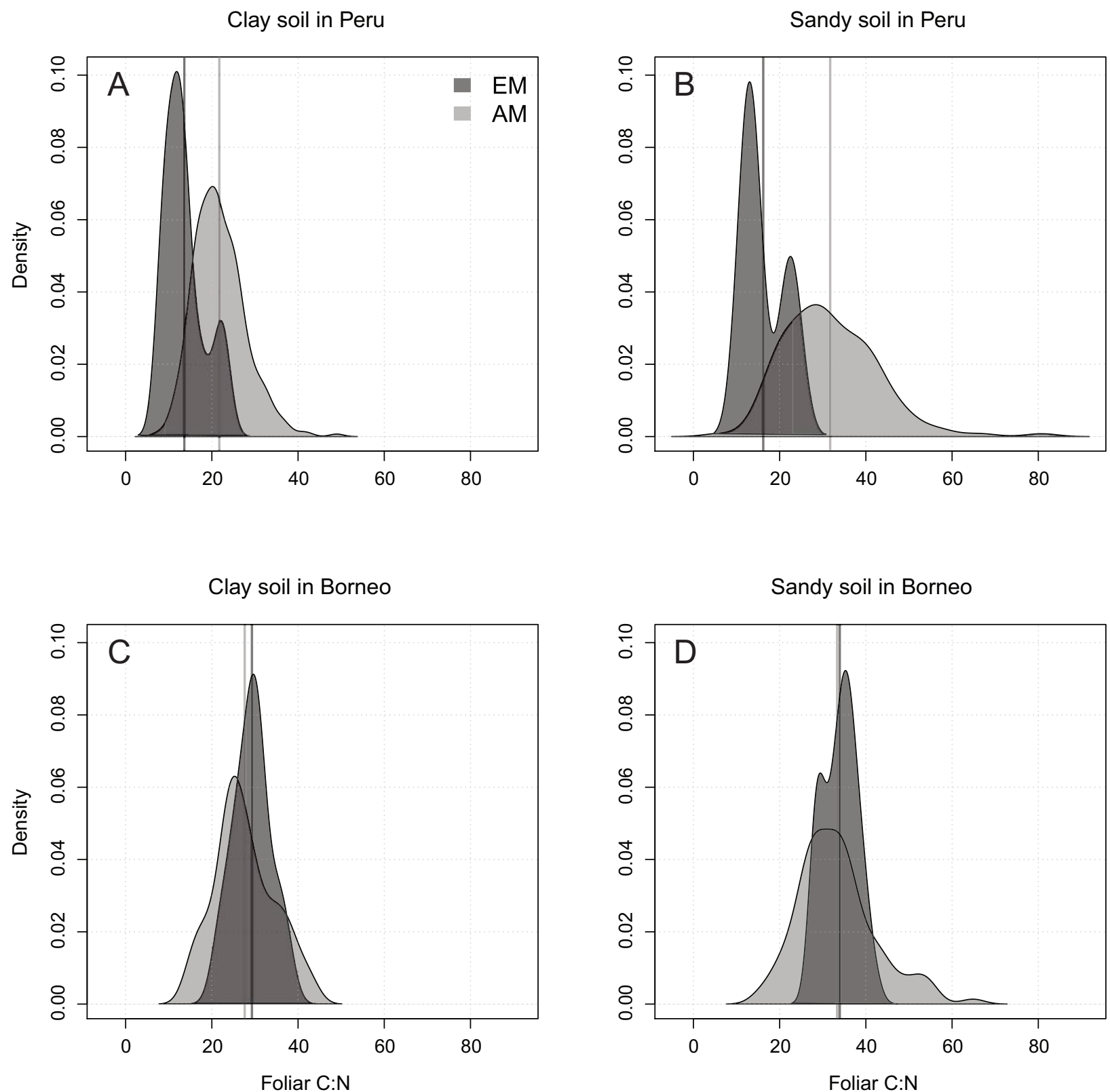

Figure 6: Probability density plots showing the frequency of tree species having particular foliar $\mathrm{C}: \mathrm{N}$ ratios under two soil conditions (less fertile sand or more fertile clay) in Borneo and Peru. Dark gray indicates ectomycorrhizal (EM) host species. Light gray indicates all other species, most of which are arbuscular mycorrhizal (AM) hosts. Dashed lines indicate means.

to AM host species in Peru, this result may reflect low statistical power due to small sample size. The number of EM species was much smaller in Peru (13 and three species) than in Borneo (17 and 35 species).

\section{Discussion}

Taken together, our simulation results suggest one potential reason why EM monodominance is favored when the species pool has a small number of EM species. Specifically, results summarized in figure 3 indicate that monodominance can emerge only when EM species phenotypes $\left(R_{i}\right)$ closely match the environmental conditions available in local forest patches $\left(H_{k}\right)$. Results presented in figure 4 indicate in turn that such optimal trait-environment matching is more likely under small species pools because EM species can then more easily track the environment. As a result, trait evolution of EM species converges toward abiotically 
Table 2: Difference in leaf trait variance between arbuscular mycorrhizal (AM) and ectomycorrhizal (EM) tree species across two edaphic habitats in Peru and Borneo

\begin{tabular}{|c|c|c|c|c|c|c|c|c|c|c|}
\hline \multirow[b]{2}{*}{ Region and habitat } & \multicolumn{2}{|c|}{ No. species } & \multicolumn{2}{|c|}{ SLA } & \multicolumn{2}{|c|}{ LCC } & \multicolumn{2}{|c|}{ LNC } & \multicolumn{2}{|c|}{$C: N$} \\
\hline & $\mathrm{AM}$ & EM & $F$ ratio & $P$ & $F$ ratio & $P$ & $F$ ratio & $P$ & $F$ ratio & $P$ \\
\hline \multicolumn{11}{|l|}{ Peru: } \\
\hline Clay & 362 & 13 & 1.11 & .45 & 1.03 & .52 & .34 & 1.00 & 1.65 & .16 \\
\hline Sand & 140 & 3 & 5.71 & .16 & 4.24 & .21 & .79 & .71 & 3.95 & .22 \\
\hline \multicolumn{11}{|l|}{ Borneo: } \\
\hline Clay & 98 & 17 & 1.15 & .40 & 3.17 & $.006^{*}$ & 4.00 & $.001^{*}$ & 2.55 & $.02^{*}$ \\
\hline Sand & 111 & 35 & 1.42 & .12 & 4.07 & $<.001^{*}$ & 7.05 & $<.001^{*}$ & 5.44 & $<.001^{*}$ \\
\hline
\end{tabular}

optimal conditions. Finally, results in figure 5 show that the reason why species do not track the environment under diverse species pools is because the complex plant-soil feedback among the many EM species obscures the effect of environmental heterogeneity on local species abundances. In other words, environmental filtering (Kraft et al. 2015a) is weaker than priority effects.

Although we have focused on mycorrhizal associations, monodominance may arise through other pathways (Peh et al. 2011). For example, a defensive ant-plant mutualism generates monodominant stands of Duroia hirstuta known as devil's gardens in the Amazon (Frederickson et al. 2005). Still, many tree species that form monodominant stands in the tropics are EM. Studies have uncovered evidence supporting a range of ways in which EM associations may generate positive plant-soil feedbacks that lead to monodominance, including common mycorrhizal networks (McGuire 2007), alteration of local nutrient economies (Corrales et al. 2016), variation in leaf chemistry (Torti et al. 2001), and EM mining of organic nitrogen (Orwin et al. 2011). Our model does not distinguish between these different mechanisms. Rather, our work is complementary to these studies in that we ask why geographic differences in species pools may lead to some tropical regions containing EM monodominant stands and other regions showing local codominance of multiple tree species of both mycorrhizal types.

We chose one simple way to represent plant-soil feedbacks. Namely, we assumed that plant-soil feedbacks were net positive and most beneficial to conspecifics. Choosing appropriate values for plant-soil feedbacks is not trivial, because in nature these feedbacks are hard to estimate. Empirical measurement of their strength should take into account multiple contributing factors, such as abiotic effects (Waring et al. 2015) and the combined effects of pathogens and mutualists (Klironomos 2002) and natural enemies (Bagchi et al. 2014). In addition, whether net feedbacks are positive or negative also depends on the choice of other heterospecific comparisons and sterilization methods used to generate the reference point. A number of other factors may influence feedback strength, such as phylogenetic relatedness (Gilbert and Webb 2007; Liu et al. 2012), local density (Comita et al. 2010; Mangan et al. 2010; Liu et al. 2012), and mycorrhizal type (Johnson et al. 2012; Dickie et al. 2014; Bennett et al. 2017).

In this study, we attempted to keep the model focused on differences in species pool size by keeping the nature of plant-soil feedback identical between AM and EM species. Through additional simulation (figs. S1, S2), we have made an initial effort to examine the robustness of our model predictions to assumptions regarding plant-soil feedback. Future iterations of this model could explore more complex plant-soil feedback structure, such as more negative (or less positive) intraspecific feedbacks and stronger positive feedbacks in EM compared with AM plants. It is also possible that EM plants are better able to make the environment less suitable for AM plants, owing to the abilities of EM fungi to access organic forms of nutrients and preempt nutrient uptake by AM fungi. This scenario can be evaluated further with our model. Finally, we assigned $R_{i}$ and $S_{i j}$ values independently, but in nature, species with similar traits - as represented by more similar values of $R_{i}$ - might have the tendency to share fungal symbionts and therefore have more positive $S_{i j}$. Phylogenetic relationships of plant species, which we did not consider in this article, may prove useful in some cases as a proxy for estimating $R_{i}$ and $S_{i j}$ values.

It is well established in plant-soil feedback theory that positive feedback causes alternative stable states, whereas negative feedback facilitates species coexistence (Bever et al. 2012). Our simulation results are consistent with this prior theory. However, most previous plant-soil feedback theories have considered interactions between only two plant species. Here, we have studied interactions among many plant species (see also Fukami and Nakajima 2011, 2013), which is the only way to directly address the effect of the number of species in the regional species pool on local community assembly driven by plant-soil feedback.

One benefit of our model is that it makes specific predictions about trait variation of plant species and about 
mycorrhiza-driven plant-soil feedbacks under different species pool sizes, specifically that divergence in the values of traits related to local environmental fit should be greater in more diverse species pools. Our trait analysis did not yield strong support for this prediction, perhaps because these are difficult effects to measure empirically, since many factors not included in our model influence trait variation in natural settings. Moreover, uncertainties regarding the mycorrhizal status (e.g., EM or AM) of plant species in different geographical locations may also have caused the poor correspondence of model predictions and empirical patterns (Forrestel et al. 2017). In addition, detecting patterns in traits across a gradient of species pool size is made difficult by the inherent correlation between species pool size and statistical power for any analysis that uses species as a unit of replication.

Our trait analysis is only a first step to begin to evaluate the empirical relevance of the hypothesis we have developed here through the simulation modeling. Research on the links between plant traits, mycorrhizal associations, and the strength of plant-soil feedback is still at an early stage of development (Laughlin et al. 2015; Cortois et al. 2016; Bennett et al. 2017), and the dearth of relevant data may in part explain the poor correspondence of our empirical results with the model predictions. We list three future directions of empirical research. First, with respect to the determinants of monodominance, we need to better understand which traits are important for tree species' fit to the local environment (Kraft et al. 2008; Fortunel et al. 2014; Laughlin et al. 2015; Forrestel et al. 2017) and how correlated different traits are with competitive abilities and the strength of plant-soil feedbacks (Uriarte et al. 2010; Fortunel et al. 2016). For example, some traits may be more closely related to competitive ability and others to niche differences (Mayfield and Levine 2010; Kraft et al. 2015b; Kunstler et al. 2016). Likewise, the patterns observed in the relationship between trait variability and monodominance may depend on which traits are involved in which kinds of interactions in the system. This possibility is supported by the fact that in our analyses of trait variation, some traits showed patterns consistent with our predictions, whereas others did not. To wit, plant-soil feedbacks involving EM species in Borneo may be mediated more strongly by the effects of trait variation in leaf structure and physical defense on litter decomposability than by the effects of foliar $\mathrm{N}$ because of the generally low fertility of soils in this Bornean forest. Thus, whether patterns of variation consistent with trait-environment matching are observed may not only depend on how correlated the traits examined are with plant-soil feedbacks but also be constrained by the local environment. Second, to complement the indirect inference of species performance and interactions through trait analysis, more direct measurements of the $C_{i j k}$ values could be helpful. One approach may be leveraging trait values in neighborhood models (Uriarte et al. 2010; Fortunel et al. 2016) as es- timates of the $C_{i j k}$ in our model to test the effects of AM and EM trees on each other's growth and survival. Third, we compared just two regions here, but it will be more informative to analyze data from more regions - including Africa, where monodominance also arises - to assess the potential applicability of our hypothesis across geographical regions with different evolutionary histories.

If species pool properties are key determinants of community assembly (Ricklefs and Schluter 1993; Zobel 2016), as we have considered in this article, a fundamental question is what causes differences in species pools among tropical regions in the first place. For example, what might explain the unusually high prevalence of EM lineages in the Asian tropics? Any understanding of why the EM pool is so large in Asia must reckon with the radiation of the Dipterocarpoideae (Dipterocarpaceae), which numbers more than 470 species (Ashton 2002). More generally, many hypotheses have been put forward to explain the disparities in tree species diversity among different tropical regions. However, there is no consensus explanation (Couvreur 2014). Some authors emphasize the relative importance of extrinsic factors, such as climate or climatic stability (Couvreur 2014), whereas others highlight intrinsic factors, such as history of diversification of different lineages in different regions, which have resulted in, for example, a diverse understory tree flora only in South America (Gentry 1993; Terborgh et al. 2016). Another potentially important intrinsic factor is EM association and its influence on the origin and maintenance of tropical tree diversity, as outlined here. Clearly, more research is needed to understand EM influences on patterns of tree monodominance and how this relates to the community assembly and diversity of regional tree floras.

\section{Conclusions}

To our knowledge, this is the first study to develop a hypothesis to explain why alternative stable states of either local EM monodominance or relative rarity arise in some tropical regions and not others. Specifically, our hypothesis is that an increase in the size of the EM tree species pool results in an increase in the complexity of biotic interactions, which in turn prevents monodominance by a single EM species. We have proposed that under a diverse EM host species pool, tree species maintain divergence in traits because of the complex plant-soil feedbacks among the many different tree species, with no species achieving a monodominant status. In contrast, under a depauperate EM host species pool, tree species experience strong selection for evolution toward the optimal abiotic conditions, allowing them to become competitive enough to form monodominant stands via positive plant-soil feedback that causes priority effects. Overall, this study highlights the importance of geographical variation in species pools in understanding the conditions under which 
community divergence results in vastly different alternative stable states.

Returning to the general topic of convergence, our goal in this article has been to point out the utility of studying the link between trait convergence and community convergence. To this end, we have explored how trait convergence may affect community convergence, using the case of tropical monodominance as an illustrative example. Although we have developed only one hypothesis, one thing that is clear from our work is that the natural historical knowledge of how convergent traits influence species interactions is essential to understanding community convergence.

\section{Acknowledgments}

We thank A. A. Agrawal for the invitation to contribute this article to the special issue arising from the Vice Presidential Symposium of the American Society of Naturalists held in Austin, Texas, in June 2016. Comments from A. A. Agrawal, P.-J. Ke, and three anonymous reviewers improved the article. T.F. thanks the National Science Foundation (NSF; DEB 1555786) and the Terman Fellowship at Stanford University for financial support as well as the Center for Macroecology, Evolution, and Climate and the Section of Microbiology at the University of Copenhagen for sabbatical support. K.G.P. was supported in part by the NSF (DEB 1249342 and RAPID 1361171) and a Department of Energy Early Career Grant (DE-SC0016097). S.E.R. was supported in part by the NSF (RAPID 1361171). Author participation: T.F. and K.G.P. designed the study; M.N. conducted and analyzed simulation in collaboration with T.F.; C.B., P.V.A.F., and C.F. collected data from Peru; S.E.R. collected data from Borneo; K.G.P. and S.E.R. analyzed data from Peru and Borneo; T.F. wrote the first draft of the manuscript; and all authors contributed to writing the manuscript.

\section{APPENDIX}

\section{Methods for Quantifying Leaf Functional Traits in Bornean Rain Forest}

\section{Study System and Species Selection}

Lambir Hills National Park (Lambir) is located in the northwestern part of Borneo in the Malaysian state of Sarawak $\left(4^{\circ} 20^{\prime} \mathrm{N}, 113^{\circ} 50^{\prime} \mathrm{E}\right)$. Lambir receives approximately $3,000 \mathrm{~mm}$ of rainfall annually, with all months averaging $>100 \mathrm{~mm}$ (Watson 1985). The region has the highest tree species richness recorded in the Paleotropics (Ashton 2005), with species in the Dipterocarpaceae dominating the forest (Lee et al. 2002). The soils and geomorphology of Lambir have been previously described (Baillie et al. 2006; Tan et al. 2009). The soils range from coarse loams that are sandstone derived, leached, nutrient depleted, and well drained with substantial raw humus, to clays that are shale derived, less nutrient depleted, and less well drained, with little raw humus. Tree community composition and demography vary across soil types, with most species exhibiting soil habitat specialization and tree demography varying across soil types (Davies et al. 2005; Russo et al. 2005). Lambir is the site of a 52-ha research plot that was established in 1991 as part of the Center for Tropical Forest Science Forest Global Earth Observatory plot network (Anderson-Teixeira et al. 2015) to monitor woody plants. All trees $\geq 1 \mathrm{~cm}$ in diameter at breast height are tagged, mapped, and dentified, and their diameters are measured to the nearest $1 \mathrm{~mm}$.

Tree species were sampled for the quantification of leaf functional traits from within and near the Lambir plot (Russo et al. 2013). The species identity of individuals sampled outside of the plot was verified using an on-site herbarium and by consultation with local botanists (S. Tan). Species were selected to encompass a wide range of families - targeting taxa contributing substantially to forest basal area in the Lambir plot - to target species-rich genera, such as Shorea (Dipterocarpaceae) and Diospyros (Ebenaceae), and to include species with a range of shade tolerance niches. For each species, juvenile (1-5 cm in diameter) and adult $(>10 \mathrm{~cm}$ in diameter) trees were sampled as much as possible, with one to 22 individuals sampled per species.

\section{Quantification of Leaf Functional Traits}

From each tree, three to five mature, sunlit, minimally damaged leaves were harvested. The petiole was cut from the lamina, which was gently cleaned of debris. Fresh leaf laminas were scanned (Canon LiDE 110), and the images were analyzed with Image J software (Schneider et al. 2012) to estimate the area of each. After oven drying at $60^{\circ} \mathrm{C}$ for 3 days, the dry weight of each lamina was recorded. The SLA $\left(\mathrm{cm}^{2} / \mathrm{g}\right)$ was calculated as fresh area divided by dry weight, and SLA was averaged across leaves of each individual. After drying, the midvein was removed from each lamina. Laminas from each individual were ground together to a fine, uniform powder and analyzed by elemental combustion for carbon and nitrogen content (Costech Analytical Elemental Combustion System 4010). For each individual, percent carbon $(\mathrm{C})$ and nitrogen $(\mathrm{N})$ were calculated as the mass of $\mathrm{C}$ (or $\mathrm{N}$ ) in the sample/dry mass of the sample $\times 100$, and $\mathrm{C}: \mathrm{N}$ ratio was calculated as percent $\mathrm{C} /$ percent $\mathrm{N}$. Trait values were averaged across individuals to obtain mean values for each tree species.

\section{Literature Cited}

Ashton, P. S. 2002. Dipterocarpaceae. Pages 182-197 in K. Kubitzki, ed. The families and genera of vascular plants. V. Flowering plants: 
Dicotyledons. Malvales, Capparales and non-betalain Caryophyllales. Springer, Berlin.

Bagchi, R., R. E. Gallery, S. Gripenberg, S. J. Gurr, L. Narayan, C. E. Addis, R. P. Freckleton, and O. T. Lewis. 2014. Pathogens and insect herbivores drive rainforest plant diversity and composition. Nature 506:85-88.

Baillie, I. C., P. S. Ashton, S. P. Chin, S. J. Davies, P. A. Palmiotto, S. E. Russo, and S. Tan. 2006. Spatial associations of humus, nutrients and soils in mixed dipterocarp forest at Lambir, Sarawak, Malaysian Borneo. Journal of Tropical Ecology 22:543-553.

Baraloto, C., S. Rabaud, Q. Molto, L. Blanc, C. Fortunel, B. Hérault, N. Dávila, I. Mesones, M. Rios, E. Valderrama, and P. V. A. Fine. 2011. Disentangling stand and environmental correlates of aboveground biomass in Amazonian forests. Global Change Biology 17:2677-2688.

Bennett, J. A., H. Maherali, K. O. Reinhart, Y. Lekberg, M. M. Hart, and J. Klironomos. 2017. Plant-soil feedbacks and mycorrhizal type influence temperate forest population dynamics. Science 355:181184.

Bever, J. D., T. G. Platt, and E. R. Morton. 2012. Microbial population and community dynamics on plant roots and their feedbacks on plant communities. Annual Review of Microbiology 66:265-283.

Brearley, F. 2012. Ectomycorrhizal associations of the Dipterocarpaceae. Biotropica 44:637-648.

Brundrett, M. C. 2002. Coevolution of roots and mycorrhizas of land plants. New Phytologist 154:275-304.

. 2009. Mycorrhizal associations and other means of nutrition of vascular plants: understanding the global diversity of host plants by resolving conflicting information and developing reliable means of diagnosis. Plant and Soil 320:37-77.

Cavender-Bares, J., K. H. Kozak, P. V. A. Fine, and S. W. Kembel. 2009. The merging of community ecology and phylogenetic biology. Ecology Letters 12:693-715.

Chapin, F. S., III, K. Autumn, and F. Pugnaire. 1993. Evolution of suites of traits in response to environmental stress. American Naturalist 142:78-92.

Chesson, P. L. 1985. Coexistence of competitors in spatially and temporally varying environments: a look at the combined effects of different sorts of variability. Theoretical Population Biology 28: 263-287.

Clements, F. E. 1936. Nature and structure of the climax. Lournal of Ecology 24:252-284.

Comita, L. S., H. C. Muller-Landau, S. Aguilar, and S. P. Hubbell. 2010. Asymmetric density dependence shapes species abundances in a tropical tree community. Science 329:330-332.

Connell, J. H., and M. D. Lowman. 1989. Low-diversity tropical rain forests: some possible mechanisms for their existence. American Naturalist 134:88-119.

Conte, G. L., M. E. Arnegard, C. L. Peichel, and D. Schluter. 2012 The probability of genetic parallelism and convergence in natural populations. Proceedings of the Roval Societv B 279:5039-5047.

Cornelissen, J., R. Aerts, B. Cerabolini, M. Werger, and M. van der Heijden. 2001. Carbon cycling traits of plant species are linked with mycorrhizal strategy. Oecologia (Berlin) 129:611-619.

Corrales, A., S. A. Mangan, B. L. Turner, and J. W. Dalling. 2016. An ectomycorrhizal nitrogen economy facilitates monodominance in a Neotropical forest. Ecology Letters 19:383-392.

Cortois, R., G. B. De Deyn, T. Schröder-Georgi, and W. H. van der Putten. 2016. Plant-soil feedbacks: role of plant functional group and plant traits. Journal of Ecology 104:1608-1617.
Couvreur, T. L. P. 2014. Odd man out: why are there fewer plant species in African rain forests? Plant Systematics and Evolution 301:1299-1313.

De Deyn, G. B., J. H. C. Cornelissen, and R. D. Bardgett. 2008. Plant functional traits and soil carbon sequestration in contrasting biomes. Ecology Letters 11:516-531.

Dickie, I. A., N. Koele, J. D. Blum, J. D. Gleason, and M. S. McGlone. 2014. Mycorrhizas in changing ecosystems. Botany 92:149-160.

Donovan, L. A., H. Maherali, C. M. Caruso, H. Huber, and H. de Kroon. 2011. The evolution of the worldwide leaf economics spectrum. Trends in Ecology and Evolution 26:88-95.

Drake, J. A. 1991. Community-assembly mechanics and the structure of an experimental species ensemble. American Naturalist 137:1-26.

Duchesne, L. C., B. E. Ellis, and R. L. Peterson. 1989. Disease suppression by the ectomycorrhizal fungus Paxillus involutus: contribution of oxalic acid. Canadian Journal of Botany 67:2726-2730

Egerton-Warburton, L., and M. F. Allen. 2001. Endo- and ectomycorrhizas in Quercus agrifolia Nee. (Fagaceae): patterns of root colonization and effects on seedling growth. Mycorrhiza 11:283-290.

Fargione, J., C. S. Brown, and D. Tilman. 2003. Community assembly and invasion: an experimental test of neutral versus niche processes. Proceedings of the National Academv of Sciences of the USA 100:8916-8920.

Forrestel, E. J., M. J. Donoghue, E. J. Edwards, W. Jetz, J. C. O. du Toit, and M. D. Smith. 2017. Different clades and traits yield similar grassland functional responses. Proceedings of the National Academv of Sciences of the USA 114:705-710.

Fortunel, C., P. V. A. Fine, and C. Baraloto. 2012. Leaf, stem and root tissue strategies across 758 Neotropical tree species. Functional Ecology 26:1153-1161.

Fortunel, C., C. E. T. Paine, P. V. A. Fine, N. J. B. Kraft, and C. Baraloto. 2014. Environmental factors predict community functional composition in Amazonian forests. Iournal of Ecology 102:145-155.

Fortunel, C., R. Valencia, S. J. Wright, N. C. Garwood, and N. J. B. Kraft. 2016. Functional trait differences influence neighbourhood interactions in a hyperdiverse Amazonian forest. Ecology Letters 19:1062-1070.

Fox, B. J. 1987. Species assembly and the evolution of community structure. Evolutionary Ecology 1:201-213.

Fransson, P. M. A., Y. K. Toljander, C. Baum, and M. Weih. 2015 Host plant-ectomycorrhizal fungus combination drives resource allocation in willow: evidence for complex species interaction from a simple experiment. Ecoscience 20:112-121.

Frederickson, M. E., M. J. Greene, and D. M. Gordon. 2005. 'Devil's gardens' bedevilled by ants. Nature 437:495-496.

Fukami, T. 2009. Convergence. Pages 188-191 in R. G. Gillespie and D. A. Clague, eds. Encyclopedia of islands. University of California Press, Berkeley.

2015. Historical contingency in community assembly: integrating niches, species pools, and priority effects. Annual Review of Ecology, Evolution, and Systematics 46:1-23.

Fukami, T., and M. Nakajima. 2011. Community assembly: alternative stable states or alternative transient states? Ecology Letters 14:973-984.

- 2013. Complex plant-soil interactions enhance plant species diversity by delaying community convergence. Iournal of Ecology 101:316-324.

Fukami, T., M. Nakajima, C. Fortunel, P. V. A. Fine, C. Baraloto, S. E. Russo, and K. G. Peay. 2017. Data from: Geographical variation in 
community divergence: insights from tropical forest monodominance by ectomycorrhizal trees. American Naturalist, Dryad Digital Repository, http://datadryad.org/resource/doi:10.5061/dryad.c0kr7.

Gentry, A. H. 1993. Diversity and floristic composition of lowland tropical forests in Africa and South America. Pages 500-547 in P. Goldblatt, ed. Biological relationships between Africa and South America. Missouri Botanical Garden Press, St. Louis.

Gilbert, G. S., and C. O. Webb. 2007. Phylogenetic signal in plant pathogen-host range. Proceedings of the National Academv of Sciences of the USA 104:4979-4983.

Gleason, H. A. 1927. Further views on the succession concept. Ecology 8:299-326.

Hart, T. B., J. A. Hart, and P. G. Murphy. 1989. Monodominant and species-rich forests of the humid tropics: causes for their cooccurrence. American Naturalist 133:613-633.

Henkel, T. W. 2003. Monodominance in the ectomycorrhizal Dicymbe corymbosa (Caesalpiniaceae) from Guyana. Journal of Tropical Ecology 19:417-437.

Horton, T. R., T. D. Bruns, and V. T. Parker. 1999. Ectomycorrhizal fungi associated with Arctostaphylos contribute to Pseudotsuga menziesii establishment. Canadian Journal of Botany 77:93-102.

Janzen, D. H. 1974. Tropical blackwater rivers, animals, and mast fruiting by the Dipterocarpaceae. Biotropica 6:69-103.

Johnson, D. J., W. T. Beaulieu, J. D. Bever, and K. Clay. 2012. Conspecific negative density dependence and forest diversity. Science 336:904-907.

Ke, P.-J., T. Miki, and T.-S. Ding. 2015. The soil microbial community predicts the importance of plant traits in plant-soil feedback New Phvtologist 206:329-341.

Kennedy, P. G., A. D. Izzo, and T. D. Bruns. 2003. There is high potential for the formation of common mycorrhizal networks between understorey and canopy trees in a mixed evergreen forest. Lournal of Ecology 91:1071-1080.

Klironomos, J. N. 2002. Feedback with soil biota contributes to plant rarity and invasiveness in communities. Nature 417:67-70.

Koele, N., I. A. Dickie, J. Oleksyn, S. J. Richardson, and P. B. Reich. 2012. No globally consistent effect of ectomycorrhizal status on foliar traits. New Phytologist 196:845-852.

Kraft, N. J. B., P. B. Adler, O. Godoy, E. C. James, S. Fuller, and J. M. Levine. 2015a. Community assembly, coexistence and the environmental filtering metaphor. Functional Ecology 29:592-599.

Kraft, N. J. B., O. Godoy, and J. M. Levine. 2015b. Plant functional traits and the multidimensional nature of species coexistence. Proceedings of the National Academv of Sciences of the USA 112:797-802.

Kraft, N. J. B., R. Valencia, and D. D. Ackerly. 2008. Functional traits and niche-based tree community assembly in an Amazonian forest. Science 322:580-582.

Kulmatiski, A., K. H. Beard, J. R. Stevens, and S. M. Cobbold. 2008. Plantsoil feedbacks: a meta-analytical review. Ecology Letters 11:980-992.

Kunstler, G., D. Falster, D. A. Coomes, F. Hui, R. M. Kooyman, D. C. Laughlin, L. Poorter, et al. 2016. Plant functional traits have globally consistent effects on competition. Nature 529:204-207.

Laughlin, D. C., S. J. Richardson, E. Wright, and P. J. Bellingham. 2015. Environmental filtering and positive plant litter feedback simultaneously explain correlations between leaf traits and soil fertility. Ecosystems 18:1269-1280.

Li, S. P., M. W. Cadotte, S. J. Meiners, Z. Pu, T. Fukami, and L. Jiang. 2016. Convergence and divergence in a long-term old-field succession: the importance of spatial scale and species abundance. Ecology Letters 19:1101-1109.
Liu, X., M. Ligan, R. S. Etienne, Y. Wang, C. Staehlin, and S. Yu. 2012. Experimental evidence for a phylogenetic Janzen-Connell effect in a subtropical forest. Ecology Letters 15:111-118.

Mangan, S. A., S. A. Schnitzer, E. A. Herre, K. M. L. Mack, M. C. Valencia, E. I. Sanchez, and J. D. Bever. 2010. Negative plant-soil feedback predicts tree-species relative abundance in a tropical forest. Nature 466:752-755.

Mayfield, M. M., and J. M. Levine. 2010. Opposing effects of competitive exclusion on the phylogenetic structure of communities. Ecology Letters 13:1085-1093.

McGuire, K. L. 2007. Common ectomycorrhizal networks may maintain monodominance in a tropical rain forest. Ecology 88:567574.

McGuire, K. L., T. W. Henkel, I. G. de la Cerda, G. Villa, F. Edmund, and C. Andrew. 2008. Dual mycorrhizal colonization of forestdominating tropical trees and the mycorrhizal status of nondominant tree and liana species. Mycorrhiza 18:217-222.

Melville, J., L. J. Harmon, and J. B. Losos. 2006. Intercontinental community convergence of ecology and morphology in desert lizards. Proceedings of the Roval Society B 273:557-563.

Mouquet, N., J. L. Moore, and M. Loreau. 2002. Plant species richness and community productivity: why the mechanism that promotes coexistence matters. Ecology Letters 5:56-65.

Nara, K. 2006a. Ectomycorrhizal networks and seedling establishment during early primary succession. New Phytologist 169:169-178.

- 2006b. Pioneer dwarf willow may facilitate tree succession by providing late colonizers with compatible ectomycorrhizal fungi in a primary successional volcanic desert. New Phytologist 171: 187-198.

Newsham, K. K., A. H. Fitter, and A. R. Watkinson. 1995. Arbuscular mycorrhiza protect an annual grass from root pathogenic fungi in the field. Lournal of Ecology 83:991-1000.

Odling-Smee, J. F., K. N. Laland, and M. W. Feldman. 2003. Niche construction: the neglected process in evolution. Princeton University Press, Princeton, NJ.

Orwin, K. H., M. U. Kirschbaum, M. G. St John, and I. A. Dickie. 2011. Organic nutrient uptake by mycorrhizal fungi enhances ecosystem carbon storage: a model-based assessment. Ecology Letters 14:493-502.

Pacala, S. W., and D. Tilman. 1994. Limiting similarity in mechanistic and spatial models of plant competition in heterogeneous environments. American Naturalist 143:222-257.

Palmgren, A. 1926. Chance as an element in plant geography. Pages 591602 in B. M. Duggar, ed. Proceedings of the International Congress of Plant Sciences, Ithaca, NY.

Peay, K. G. 2016. The mutualistic niche: mycorrhizal symbiosis and community dynamics. Annual Review of Ecology, Evolution, and Systematics 47:143-164.

Peay, K. G., C. Baraloto, P. V. A. Fine. 2013. Strong coupling of plant and fungal community structure across western Amazonian rainforests. ISME Journal 7:1852-1861.

Peay, K. G., S. E. Russo, K. L. McGuire, Z. Lim, J. P. Chan, S. Tan, and S. J. Davies. 2015. Lack of host specificity leads to independent assortment of dipterocarps and ectomycorrhizal fungi across a soil fertility gradient. Ecology Letters 18:807-816.

Peh, K. S. H., S. L. Lewis, and J. Lloyd. 2011. Mechanisms of monodominance in diverse tropical tree-dominated systems. $\underline{\text { Journal of }}$ Ecology 99:891-898.

Pennington, T. D., C. Reynel, and A. Daza. 2004. Illustrated guide to the trees of Peru. Hunt, Sherborne. 
Petraitis, P. 2013. Multiple stable states in natural ecosystems. Oxford University Press, Oxford.

Phillips, R. P., E. Brzostek, and M. G. Midgley. 2013. The mycorrhizalassociated nutrient economy: a new framework for predicting carbon-nutrient couplings in temperate forests. New Phytologist 199:41-51.

Read, D. J. 1991. Mycorrhizas in ecosystems. Experientia 47:376-391. Reich, P. B. 2014. The world-wide 'fast-slow' plant economics spectrum: a traits manifesto. Journal of Ecology 102:275-301.

Reich, P. B., M. B. Walters, and D. S. Ellsworth. 1997. From tropics to tundra: global convergence in plant functioning. Proceedings of the National Academy of Sciences of the USA 94:13730-13734.

Richards, P. W. 1952. The tropical rain forest, an ecological study. Cambridge University Press, Cambridge.

Ricklefs, R. E., and D. Schluter, eds. 1993. Species diversity in ecological communities. University of Chicago Press, Chicago.

Russo, S. E., S. J. Davies, D. A. King, and S. Tan. 2005. Soil-related performance variation and distributions of tree species in a Bornean rain forest. Journal of Ecology 93:879-889.

Russo, S. E., A. Kochsiek, J. Olney, L. Thompson, A. E. Miller, and S. Tan. 2013. Nitrogen uptake strategies of edaphically specialized Bornean tree species. Plant Ecology 214:1405-1416.

Samuels, C. L., and J. A. Drake. 1997. Divergent perspectives on community convergence. Trends in Ecology and Evolution 12:427-432.

Schneider, C. A., W. S. Rasband, and K. W. Eliceiri. 2012. NIH Image to ImageJ: 25 years of image analysis. Nature Methods 9:671675.

Schröder, A., L. Persson, and A. M. de Roos. 2005. Direct experimental evidence for alternative stable states: a review. Oikos 110:3-19.

Smith, M. E., T. W. Henkel, J. K. Uehling, A. K. Fremier, H. D. Clarke, and R. Vilgalys. 2013. The ectomycorrhizal fungal community in a Neotropical forest dominated by the endemic dipterocarp Pakaraimaea dipterocarpacea. PLoS ONE 8:e55160.

Stern, D. L. 2013. The genetic causes of convergent evolution. Nature Reviews Genetics 14:751-764.

Sutherland, J. P. 1974. Multiple stable points in natural communities. American Naturalist 108:859-873.

Tedersoo, L., T. W. May, and M. E. Smith. 2010. Ectomycorrhizal lifestyle in fungi: global diversity, distribution, and evolution of phylogenetic lineages. Mvcorrhiza 20:217-263.

Terborgh, J., L. C. Davenport, R. Niangadouma, E. Dimoto, J. C. Mouandza, O. Schultz, and M. R. Jaen. 2016. The African rainforest: odd man out or megafaunal landscape? African and Amazonian forests compared. Ecography 39:187-193.

Teste, F. P., P. Kardol, B. L. Turner, D. A. Wardle, G. Zemunik, M. Renton, and E. Laliberté. 2017. Plant-soil feedback and the maintenance of diversity in Mediterranean-climate shrublands. Science 355:173-176.
Torti, S. D., P. D. Coley, and T. A. Kursar. 2001. Causes and consequences of monodominance in tropical lowland forests. American Naturalist 2:141-153.

Uriarte, M., N. G. Swenson, R. L. Chazdon, L. S. Comita, W. J. Kress, D. Erickson, J. Forero-Montana, J. K. Zimmerman, and J. Thompson. 2010. Trait similarity, shared ancestry and the structure of neighbourhood interactions in a subtropical wet forest: implications for community assembly. Ecology Letters 13:1503-1514.

Van Nes, E. H., and M. Scheffer. 2004. Large species shifts triggered by small forces. American Naturalist 164:255-266.

Waring, B. G., L. Alvarez-Cansino, K. E. Barry, K. K. Becklund, S. Dale, M. G. Gei, A. B. Keller, et al. 2015. Pervasive and strong effects of plants on soil chemistry: a meta-analysis of individual plant 'Zinke' effects. Proceedings of the Roval Society B 282: 20151001.

Zobel, M. 2016. The species pool concept as a framework for studying patterns of plant diversity. Lournal of Vegetation Science 27:818.

\section{References Cited Only in the Online Appendixes}

Anderson-Teixeira, K. J., S. J. Davies, A. C. Bennett, E. B. GonzalezAkre, H. C. Muller-Landau, S. J. Wright, K. Abu Salim, et al. 2015. CTFS-ForestGEO: a worldwide network monitoring forests in an era of global change. Global Change Biology 21:528-549.

Ashton, P. S. 2005. Lambir's forest: the world's most diverse known tree assemblage? Pages 191-216 in D. W. Roubik, S. Sakai, and A. A. Hamid, eds. Pollination ecology and rain forest diversity, Sarawak Studies. Springer, New York.

Davies, S. J., S. Tan, J. V. LaFrankie, and M. D. Potts. 2005. Soilrelated floristic variation in the hyperdiverse dipterocarp forest in Lambir Hills, Sarawak. Pages 22-34 in D. W. Roubik, S. Sakai, and A. A. Hamid, eds. Pollination ecology and rain forest diversity, Sarawak Studies. Springer, New York.

Lee, H. S., S. J. Davies, J. V. LaFrankie, S. Tan, T. Yamakura, A. Itoh, T. Ohkubo, and P. J. Ashton. 2002. Floristic and structural diversity of mixed dipterocarp forests in Lambir Hills National Park, Sarawak, Malaysia. Journal of Tropical Forest Science 14: 379-400.

Tan, S., T. Yamakura, M. Tani, P. Palmiotto, J. D. Mamit, C. S. Pin, S. Davies, P. Ashton, and I. Baillie. 2009. Review of soils on the 52-ha long term ecological research plot in mixed dipterocarp forest at Lambir, Sarawak, Malaysian Borneo. Tropics 18:61-86.

Watson, H. 1985. Lambir Hills National Park: resource inventory with management recommendations. National Parks and Wildlife Office, Kuching.

Symposium Editor: Anurag A. Agrawal 